\section{Charcot and his visits to Britain}

\author{
Raymond Hierons
}

Until the second world war, Charcot was widely recognised as one of the leading medical men in Europe, an outstanding neurologist and teacher, whose lectures were attended not only by doctors but also by distinguished lay people. His renown was largely due to The Story of San Michele, the autobiography of Axel Munthe, a medical practitioner, which had a chapter devoted to Charcot (although it presented a derogatory picture of him). ${ }^{1}$ As with many medical students of my generation, Munthe's book made a deep impression on me, and this was reinforced when, shortly after the second world war, I visited Charcot's old hospital, the Salpêtrière, in Paris. Now, 100 years after Charcot's death, it is an appropriate time to remember him and to record his love of the English language and his visits to Britain.

\section{Life and work}

Jean-Martin Charcot was born in modest circumstances on 29 November 1825 in Paris. He entered the Paris faculty of medicine and spent his internship mainly at the Salpêtrière, where he and his friend, Vulpian (who was later to achieve fame as a pathologist and physiologist), recognised the immense possibilities for clinical research in that vast institution for the old, infirm, and deranged.

The early part of Charcot's life was devoted to general medicine. He detected the excessive amount of uric acid in gout; recognised the lobular structure of the lung, liver, and kidney; introduced routine temperature taking in everyday hospital practice; and first described the periodic fever following gall stone colic. Charcot also first described intermittent claudication, which he recognised in an account of a horse that started to hobble after a few minutes of trotting, but walked normally after a brief rest, only to hobble again.

From about 1868 Charcot turned his attention to the nervous system. Before he described the clinical manifestations of multiple sclerosis this diagnosis was never considered during life. He recognised the lesions in the olfactory nerves and in the spinal nerve roots, findings that have received attention and confirmation only recently-as have his observations on the miliary aneurysms responsible for cerebral haemorrhage. Charcot's wide reading included Parkinson's small monograph of 1817 , and it was he who named paralysis agitans after the Shoreditch physician.

The neuropathic joint was invariably called Charcot's joint in English 50 and more years ago, when tabes was a common condition. Charcot gave the first clinicopathological account of amyotrophic lateral sclerosis-motor neurone disease-which is still called Charcot's disease in mainland Europe. ${ }^{2}$

Charcot was opposed to animal experiments, but with his junior, Pitres, he made considerable contributions, from clinical observations to the study of cerebral localisation. Like Hughlings Jackson, he was fascinated by focal epilepsy, but recognised the greater achievements of his English colleague and introduced the name Jacksonian epilepsy.

These neurological contributions made Charcot known throughout the medical world, but it was his studies on hysteria and hypnotism that brought his name before the general public. His conclusions were flawed but came about as a result of the administrative changes at the Salpêtrière when the hysterical patients were transferred to the wards of the chronic epileptic patients. As Pierre Marie wrote 40 years later, "Charcot, involuntarily by force of circumstances, was plunged into hysteria. As a result La Grande Hysterie of the Salpêtrière came into existence. It did not exist anywhere else." 3

Charcot was constantly preoccupied by the differentiation of the organic from the hysterical. He greatly influenced Freud and expressed the idea in his presence that hysteria is based on repression and always has a sexual content.

\section{Charcot's personality}

Axel Munthe's autobiography describes Charcot as "short of stature, with the chest of an athlete and the neck of a bull . . . a most imposing man to look at. A white clean-shaven face, a low forehead, cold penetrating eyes, an aquiline nose, sensitive cruel lips, the mask of a Roman emperor." The account goes on to consider him "a tyrant who was feared by his patients and his assistants, for whom he seldom had a kind word of encouragement in exchange for the superhuman amount of work he imposed upon them. He was indifferent to the sufferings of his patients; he took little interest in them from the day of establishing the diagnosis until the day of the post mortem examination."

Reading this book again after half a century, I doubt its accuracy. As a medical student in Paris, Munthe would certainly have attended Charcot's lectures and demonstrations, but he never had any close association with Charcot. He did not pass the competitive examination to be an intern or hold any junior hospital post in Paris. Munthe's attitude to Charcot may also have been affected by an incident in which he took a young hysterical woman to live in his home-to escape, as he said, from Charcot's ward. When Charcot heard about this he threatened police action, but instead had Munthe taken outside the hospital and ordered that he was not to be allowed to enter again.

Munthe's description was written more than 40 years after he was expelled from the Salpêtrière. Perhaps he took some of it from another disparaging account written a few years earlier, with very similar phraseology, by Léon Daudet, son of the famous writer, Alphonse. The father was a close friend, neighbour, and patient of Charcot, but after Charcot's death a bitter feud developed between the two families, possibly connected with the broken engagement between Charcot's daughter and Léon.

Munthe's harsh remarks about Charcot must be 
open to question since accounts by others, including Freud and Osler, give a very different and most sympathetic picture of Charcot. They describe him as courteous to his assistants and kind to his patients. ${ }^{4}$ Many, however, found him to have a rather cold exterior, probably as a cover for extreme shyness.

In the famous painting by André Brouillet (fig 1) of one of Charcot's Friday lectures we see Babinski (supporting the patient) and Gilles de la Tourette (seated in the middle and wearing an apron). Most of the others present achieved distinction in medicine or neurology, including Marie, Raymond, Joffroy, Brissaud, and Bourneville. Charcot's son, then an intern, is seen leaning against the window with his arms folded. The patient made a full recovery and then worked in the photographic department of the Salpêtrière. Freud had a copy of this picture in his consulting room in Vienna and clearly treasured it, for when he fled to London in 1938 he hung it over the consulting room couch, and it remains there today.

Fig 2 shows Charcot's "Leçons du mardi," when patients were brought before him whom he had not previously seen. Freud wrote of these occasions, when he would "speak extemporaneously, put aside his authority on occasion in one case that he could arrive at no diagnosis and in another that he had been deceived by appearances; and he never appeared greater to his audience than when by giving the most detailed account of his processes of thought and by showing the greatest frankness about his doubts and hesitations; he had thus sought to narrow the gulf between teacher and pupil."”

Charcot's personality seems to have been less mercurial and more deliberate than that of many of his countrymen. Every thought was carefully matured; he assembled his material and deliberated long before reaching his conclusions. All his writings contain the most detailed analyses of the literature ranging from antiquity. He covered science, art, history, and literature.

His knowledge of British publications was truly amazing. Particularly impressive are his references to Thomas Willis at a time when Willis was neglected and somewhat denigrated in his own country (largely due to the physiologist Sir Michael Foster). Charcot makes many references to Sydenham, Parkinson, Todd, Graves, Brodie, Hilton, and Paget. His knowledge of the international literature can be appreciated by a prank carried out by Weir Mitchell. Weir Mitchell was an impressive figure in nineteenth century American neurology and a talented poet and novelist. One of his

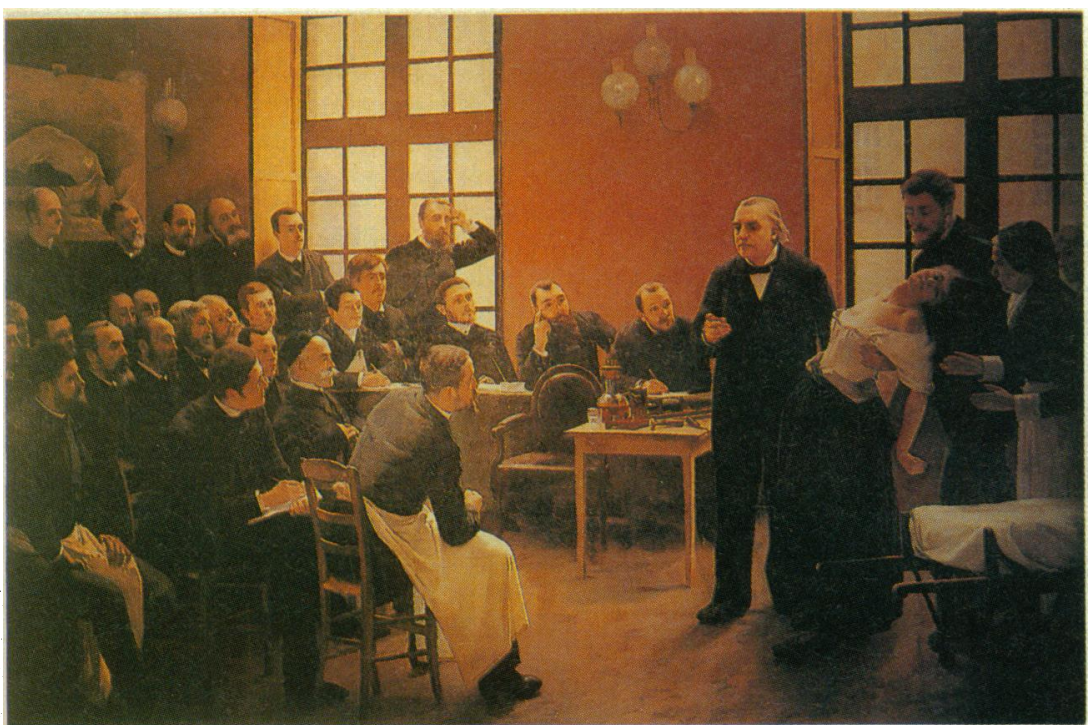

Fig 1-Charcot presents a hysterical patient to his colleagues at the Salpetrière. Reproduced by permission of Neurological Hospital, Lyons

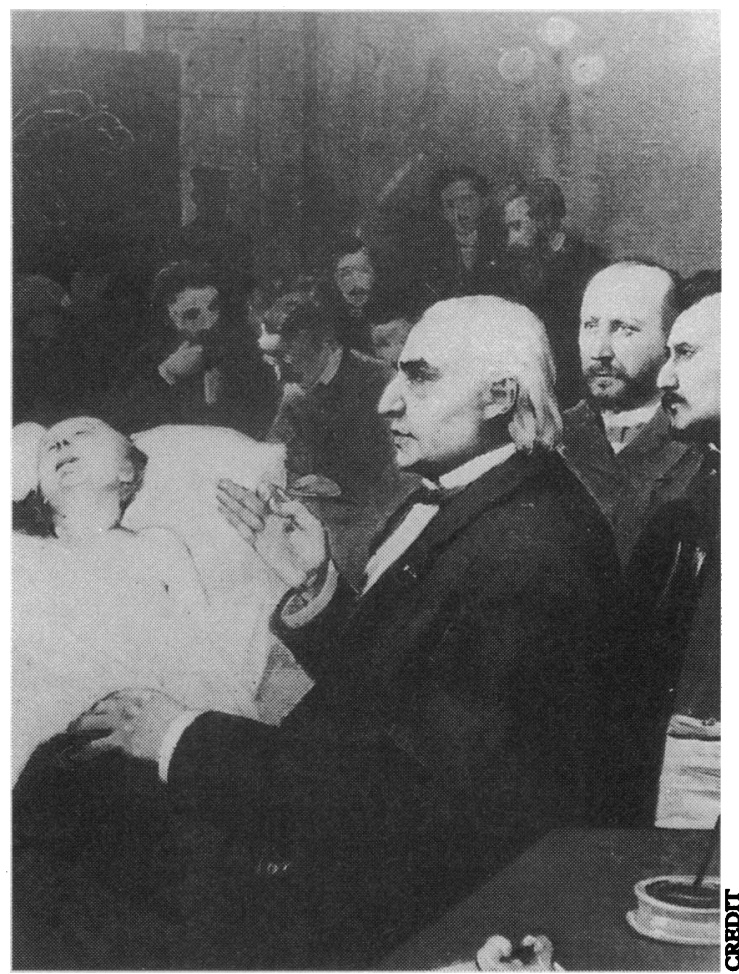

Fig 2-A "lecon du mardi,"' reproduced by permission of National Hospital, Queen Square

contributions was the so called "rest cure" for neurotic disorders, which was popular well into this century. In 1873 he visited Paris and was anxious to find out what manner of man was Charcot. He pretended to be a patient and gave an account to Charcot of neurasthenic symptoms. When Charcot learned that this patient was soon to return to the United States, he urged him to see Weir Mitchell, saying that he knew more about this condition than anyone else.?

\section{Visits to Britain}

Charcot spoke extremely good English and was an honorary member of the BMA and several medical societies on this side of the Channel. The first of his visits was in the early 1860 s, when he came to a number of London teaching hospitals and the Hunterian Museum of the Royal College of Surgeons. In 1869 he accompanied Brown-Sequard to the annual BMA meeting in Leeds. In those days these gatherings were important to the whole profession, as specialist meetings did not then exist.

The following year, during the siege of Paris by the Germans, the Salpêtrière was shelled and there were epidemics of smallpox, cholera, and typhoid. Charcot remained in Paris, but he sent his wife and three children to stay in London with the artist Casella.

At this time Charcot's name became well known to English doctors. Many translations of his lectures appeared in the $B M \mathcal{F}$ and Lancet, and there were numerous abstracts of his publications in British journals, as well as reviews of his books. In 1872 he visited Dublin with a delegation of French physicians. Five years later he gave one of the principal addresses to the BMA meeting in Manchester, on the relations of tuberculosis and caseous pneumonia. ${ }^{8}$ At that visit he presented the London College of Surgeons with a specimen of neuropathic shoulder joint which he had first described a few years earlier. This specimen is still to be seen in the Hunterian Museum as it survived the bombing of the college in 1941 .

In 1878 a number of distinguished international visitors spent several days on his wards and at his lectures. These included the famous German patho- 
logist, Virchow, several Edinburgh professors, and also the editor of the $B M \mathcal{F}$, Ernest Hart. A full account of this visit appeared later in the $B M F$ from Gamgee, professor of physiology in Manchester.'

In August 1881 the seventh international medical congress took place in London, with over $\mathbf{3 0 0 0}$ participants. Charcot discussed neuropathic joint disease and showed a wax modet of the skeleton of a women who had the condition in a knee, hip, both shoulders, and the jaw as a result of tabes. He also took part in the physiology section, and the high temperature of the discussion on localisation of function in the cerebral cortex is still evident from a reading of the proceedings. ${ }^{10}$

In the main hall of the congress there were busts of Pasteur, Virchow, and Charcot, and at the final dinner at the Crystal Palace large firework portraits of Paget, Charcot, and von Langenbech (the leading continental surgeon of the time) appeared in the sky.

Figure 3 shows Charcot's own sketch of "a bad morning" as seen from a hotel in Llandudno the following year. On that visit he was almost killed in north Wales by a drunken carriage driver.

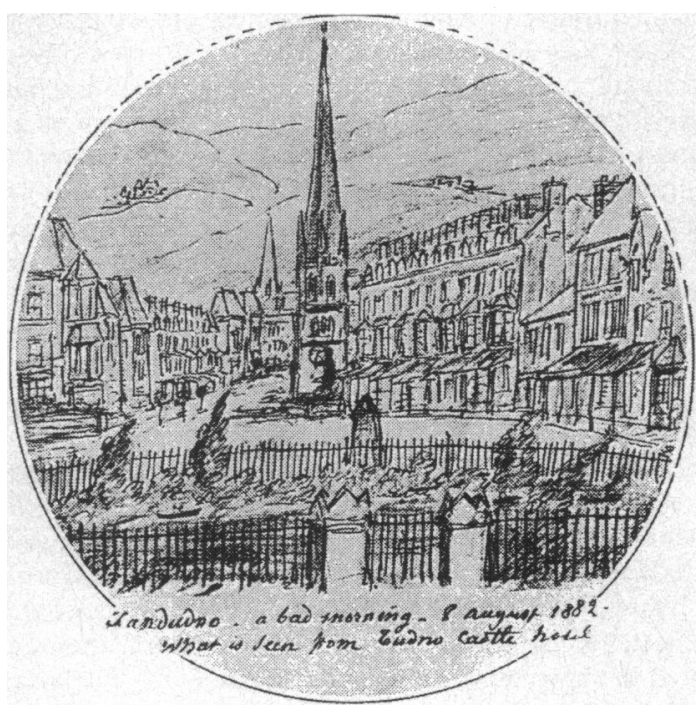

Fig 3-" $A$ bad morning" in Llandudno. From $H$ Meige, "Charcot Artiste" (Paris: Masson, 1925)

In July 1886 he was again at the BMA annual meeting, in Brighton, and spoke before Hughlings Jackson, following Victor Horseley's address on brain surgery. Charcot was invited to give the main address at the BMA in 1889 but had to be elsewhere. By 1891 his physical health was failing after he had suffered a myocardial infarction. In spite of this he made a final visit to Bournemouth in June 1893, less than two months before his death.

\section{Scandal involves doctor-financier}

In the late 1880 s France was shaken by a financial scandal which implicated members of the chamber of deputies and even ministers. The French Panama Canal Company had floated a lottery to raise money to build the canal. One of the adventurers concerned was Cornelius Herz, an American citizen and a graduate of the Paris medical school. After the scandal he came to England and lived in Bournemouth. The French government applied for his extradition in January 1893 , and a warrant for his arrest was issued on charges of fraud. At that time the only person who could decide on extradition was the Bow Street magistrate, and the law did not allow the hearing to take place other than at Bow Street. Herz's doctors in Bournemouth said that he could not be moved without serious peril to his life.

At the request of the French government Charcot and Brouardel (dean of the Paris medical school) went to Bournemouth in June 1893 to examine Herz. They visited him at midnight and again the next day and agreed that he was unfit to travel. Surprisingly, anonymous annotations appeared in the $B M F$ and Lancet claiming Herz's innocence. ${ }^{11} 12$ These were almost certainly written by eminent medical men who had examined Herz. One of them, the eye specialist from King's College Hospital, Professor Malcolm M'Hardy, wrote to the Times on similar lines, and the editor gave weight to his words by stating that the writer was a grandson of Nelson's signal lieutenant. ${ }^{13} 14$

At the consultation Herz is reported as having said to Charcot, "You do not recognise me, Dr Charcot"; Charcot replied that he had never seen him before. "You are mistaken Sir," returned the patient, "I was an intern under you in 1867 when you replaced Dr Marrotte at the Pitié Hospital. I can see you now sketching a blood clot from the femoral vein which was the shape of a serpent's head." Dr Charcot remembered these details.

Lawyers for Herz claimed on his behalf that as he was a grand officer of the Legion of Honour the warrant was technically flawed. An Act of Parliament was eventually passed allowing the London magistrate to hear the case at the bedside, and Herz was allowed to remain in Bournemouth. ${ }^{15}$

\section{Who was Charcot?}

Charcot's son, Jean, featured in Brouillet's painting, had wanted to be a naval officer but, no doubt as a result of his father's authority, qualified in medicine. Several years after his father's death he went to sea and eventually achieved fame as a polar explorer. In 1936 his ship was lost in a cyclone. Today, if you ask an educated Frenchman who Charcot was he would probably recall Commander Charcot of the Pourquoi Pas. To doctors, however, Jean-Martin Charcot is remembered as one of the greatest of medical teachers, who honoured France and the medical world by his vast work.

I am grateful to Dr David Berry for help with the final draft; Mrs Deidre Zincraft for secretarial help; Professor R Labauge of Montpelier and Dr M Boucher of Lyons for help with figure 1; Dr R Kochen and the photographic department of the National Hospital, Queen Square, for figure 2; and Dr A $\mathrm{D}$ Leigh and Mr R Aspen for advice.

1 Munthe A. The story of San Michele. London: John Murray, 1929.

2 Charcot J-M. Clinical lectures on diseases of the spinal cord. Lecture number 2. Symptomatology of lateral amniotropic sclerosis. Lancet 1874;ii:73-4, 149-50.

3 Maria P. Eloge de J-M Charcot. Revue Neurologique 1925;1:736-45.

4 Freud EL, ed. Letters of Sigmund Freud. London: Hogarth Press, 1961: vol 1, 7-15; vol 3, 11-23. (Translated by T Stern and J Stern.)

5 Osler W. Jean-Martin Charcot. Fohns Hopkins Hospital Bullexin 1893;4:87-8.

5 Freud S. Standard edition of the complete psychological works of Sigmund Freud. Vol 1. London: Hogarth Press, 1966:9. (Translated by J Strachey.)

7 Earnest E. $S$ Weir Mitchell, novelist and physician. Philadelphia: University of Pennsylvania Press, 1950:241-2.

8 Charcot J-M. Relations of tuberculosis and caseous pneumonia. BMF 1877;ii:314-5.

9 Gamjee A. Account of demonstration of hystero-epilepsy given by Professor Charcot. BMF1878;ii:454-8.

10 MacCormack Sir W, ed. Transactions of the International Medical Congress. London: Kolekman, 1881.

11 [Annotations on C Herz.] BMF 1893;ii:858, 885, 1009.

12 [Annotations on C Herz.] Lancet 1893;ii:885, 1273.

13 M'Hardy M. [Letters.] Times 1893 October 23, November 6.

14 [Editorial.] Times 1893 November 10.

15 Documents on C Herz. Public Records Office, H.O. 144-492. 